\title{
Citation Laureates 2018
}

\section{Web of Science}

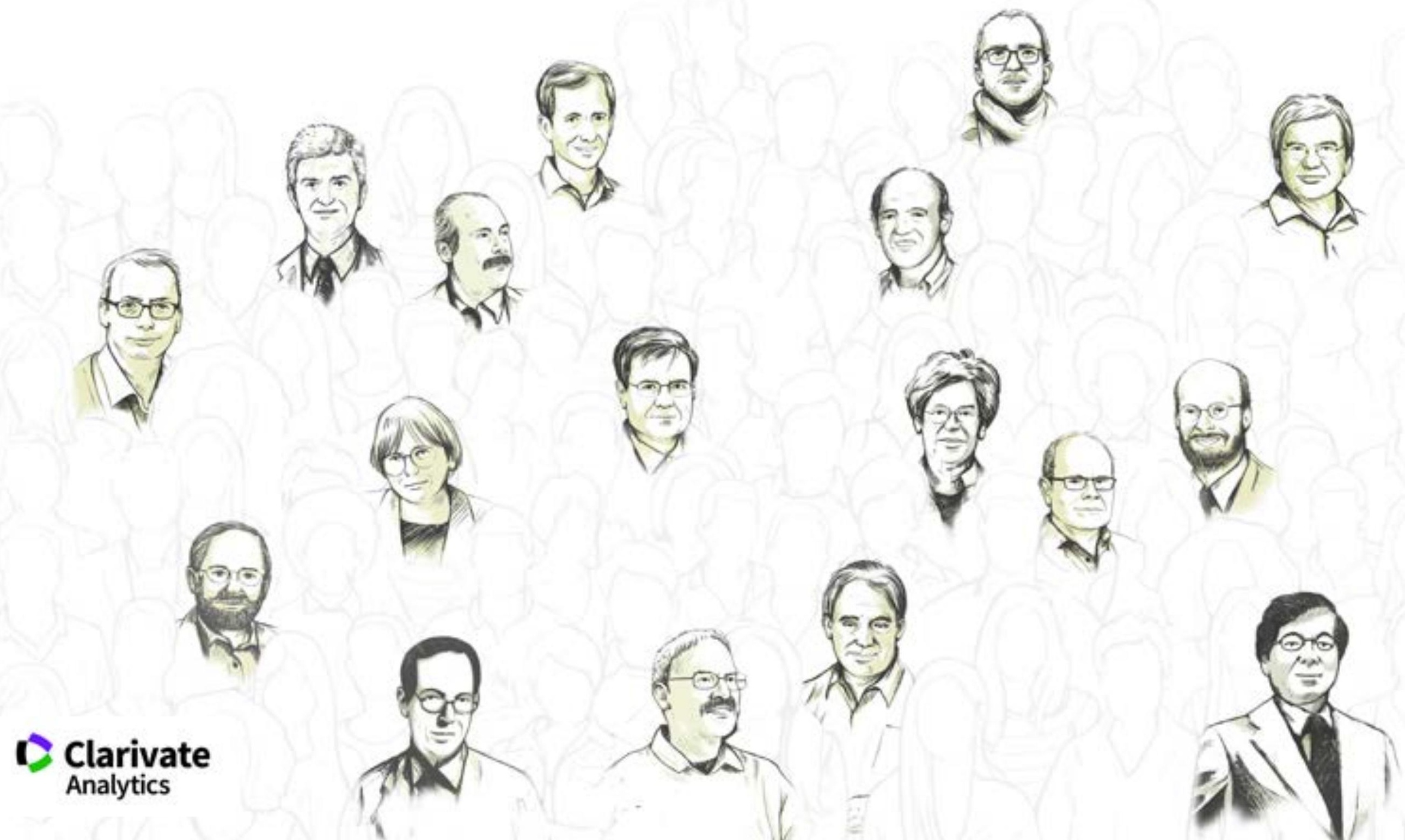




\section{Of Nobel Class}

Clarivate Analytics announces the 2018 additions to its cohort of Citation Laureates - researchers whose work is deemed to be of Nobel stature, as attested by markedly high citation tallies recorded in the Web of Science citation index.
On October 1, 2018, the Nobel Assembly will vote to confer science's highest honor and announce the first of the 2018 Nobel Prizes. While this annual rite inspires worldwide speculation about possible winners, Clarivate Analytics has since 2002 brought special insight into identifying researchers likely to receive Nobel recognition.

In selecting these Nobel-class researchers, our analysts focus on data in Web of Science, an online resource reflecting the indexed contents of more than 34,000 scientific journals and other source materials. Of particular interest for us are authors of extremely highly cited papers (those cited more than 1,000 times in the Web of Science Core Collection). Each citation is a marker of influence, a "pellet of peer recognition," as the late sociologist of science Robert K. Merton observed. He also noted that a citation is a repayment of an intellectual debt, since authors use citations to acknowledge the previous, foundational work on which they are building 
Papers cited more than 1,000 times are rarities. The table below shows the citation distribution of articles and proceedings papers indexed in the Web of Science from 1970 to 2018

\begin{tabular}{|c|c|c|}
\hline Citations & $\begin{array}{c}\text { Number } \\
\text { in range }\end{array}$ & $\begin{array}{c}\text { Cumulative } \\
\text { count }\end{array}$ \\
\hline $100,000-243,788$ & 2 & 2 \\
\hline $50,000-99,999$ & 9 & 11 \\
\hline $10,000-49,999$ & 171 & 182 \\
\hline $5,000-9,999$ & 532 & 714 \\
\hline $3,000-4,999$ & 1,145 & 1,859 \\
\hline $2,000-2,999$ & 2,325 & 4,184 \\
\hline $1,000-1,999$ & 12,112 & 16,296 \\
\hline $500-999$ & 48,762 & 65,058 \\
\hline $0-499$ & 45,493, & $45,558,962$ \\
\hline
\end{tabular}

Only 16,300 (or .04 percent) have been cited 1,000 or more times.

Only 4,200 (or .01 percent) have been cited 2,000 or more times.

\section{Out of some 45.5 million papers since 1970......}

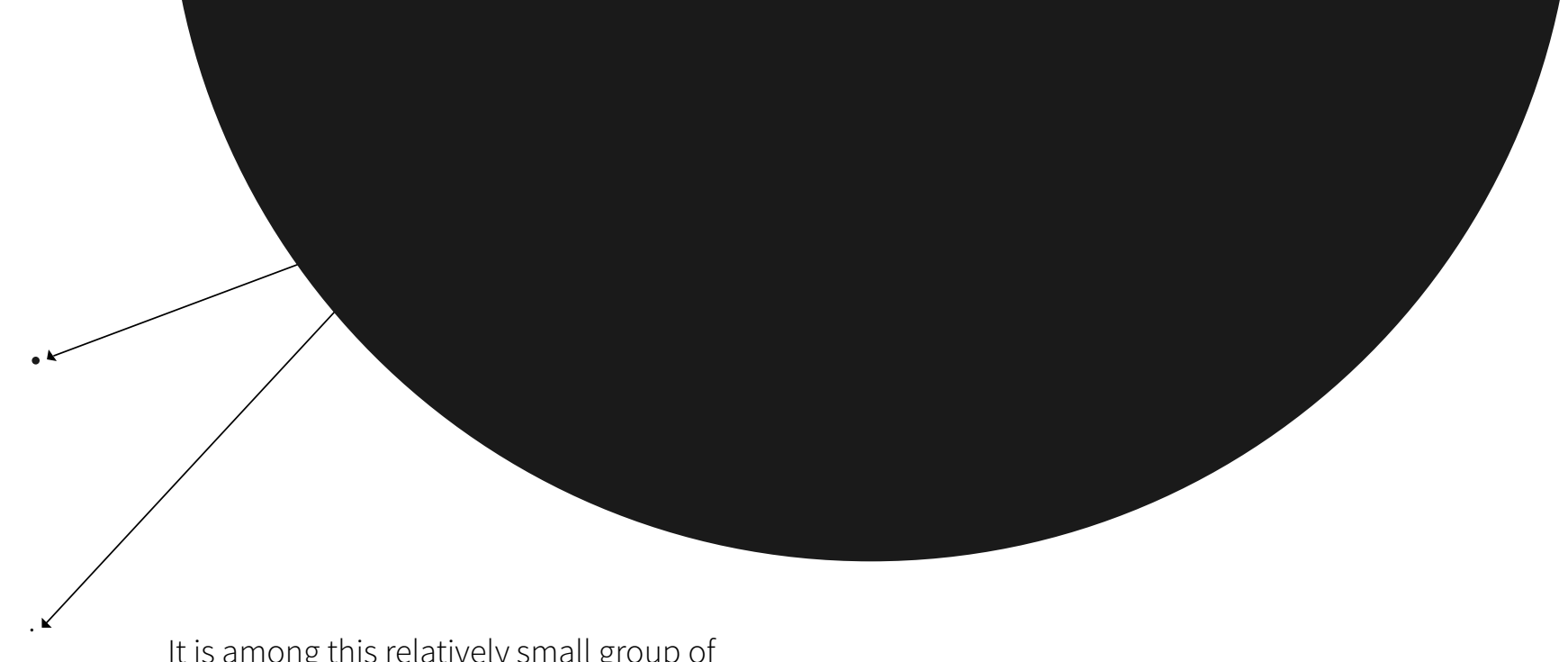

all group of publications that the names of most past and future Nobel laureates may be found as authors. 
In seeking Citation Laureates, our analysts refine their search for instances in which this highly cited work is clearly associated with a significant discovery or advance on a scale that the Nobel committees typically reward. Another pointer is provided by "predictor" prizes that often precede Nobel recognition

- for example, the Lasker Awards in biomedicine. Information on receipt of prestigious awards supplements our quantitative, citation-based analysis - an approach unique to Clarivate in identifying Nobel-worthy scientists with qualitative considerations arising

from past peer-review decisions.

Candidates who meet these criteria are officially designated Citation Laureates.

The 2018 class of honorees joins a group that now numbers upwards of 300.

Of these, 46 have received a call to Stockholm, 27 within two years of being designated Citation Laureates. For the current selectees and those named in previous years, exactly when their call might come, or even if it will arrive in time to conform to Alfred Nobel's stipulation that the prize shall honor only living recipients, is impossible to say.

In many instances, a Nobel Prize calls out work that took place decades ago, and attempting to forecast precisely which achievement is due for a prize can be a challenge. Therefore, as in every year, this latest batch of Citation Laureates should not be considered literal predictions for the 2018 Nobel Prizes.

\section{The Citation Laureates are of Nobel class and worthy candidates for selection in this or future years.}

Citation Laureates 2018 


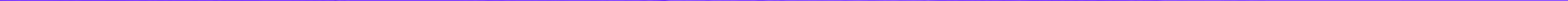


We recognize Solomon H. Snyder for his identification of receptors for many neurotransmitters and psychotropic agents, including brain receptors associated with opiates. His insights have been applied in the development of many common prescription drugs, such as compounds for pain control.
For his identification of receptors for many neurotransmitters and psychotropic agents

\section{Solomon H. Snyder}

Distinguished Service Professor of Neuroscience, Pharmacology and Psychiatry, Johns Hopkins University School of Medicine, Baltimore, USA 
For the discovery of We recognize Napoleone Ferrara for vascular endothelial the discovery of vascular endothelial growth factor (VEGF),

a key regulator of angiogenesis growth factor (VEGF), a key regulator of angiogenesis, the process in which new blood vessels are formed, both in healthy tissue and in cancerous cells. Ferrara's work has led to the development of drugs that inhibit blood-vessel growth in cancer and in blinding eye disorders such as age-related macular degeneration.
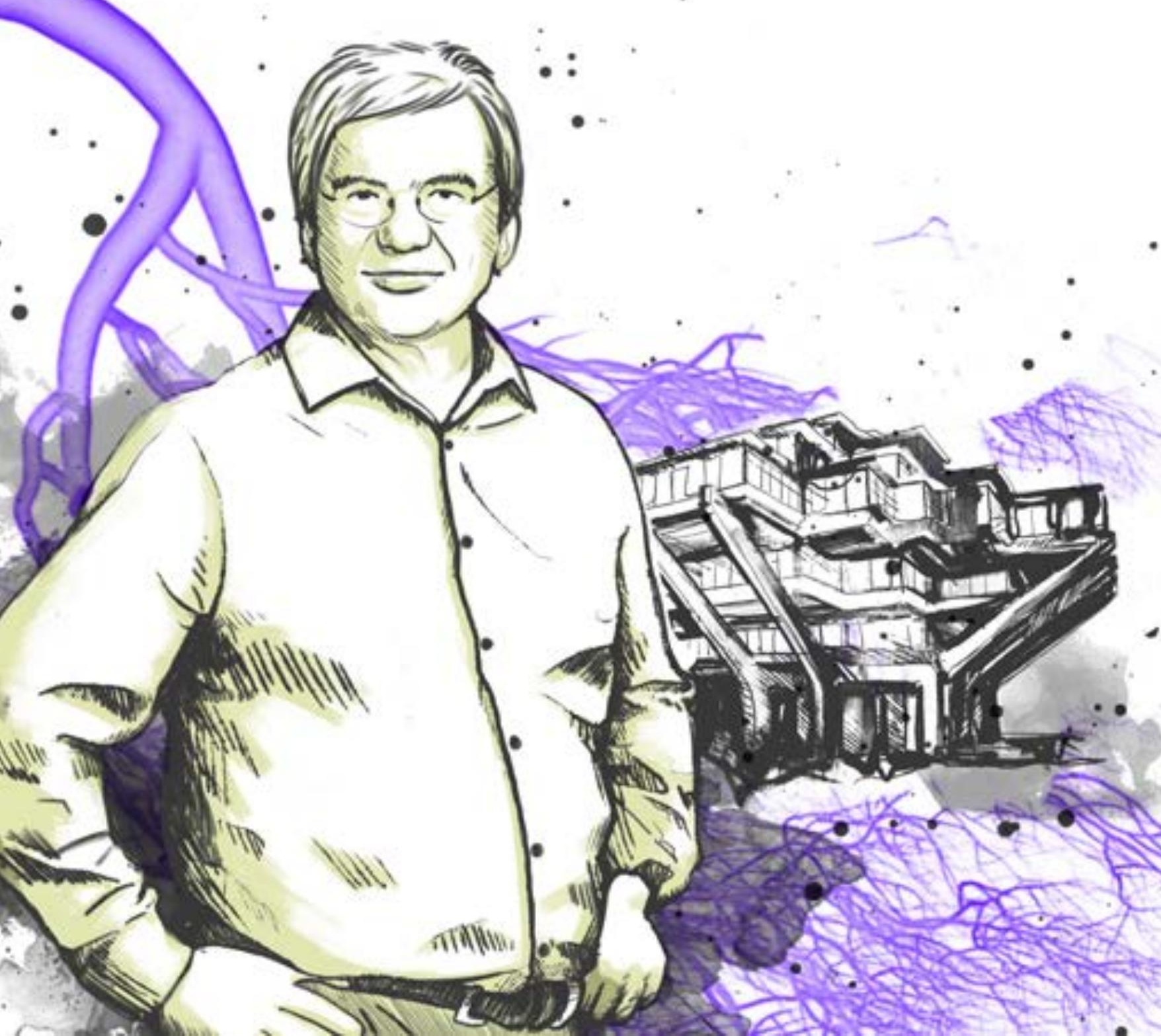


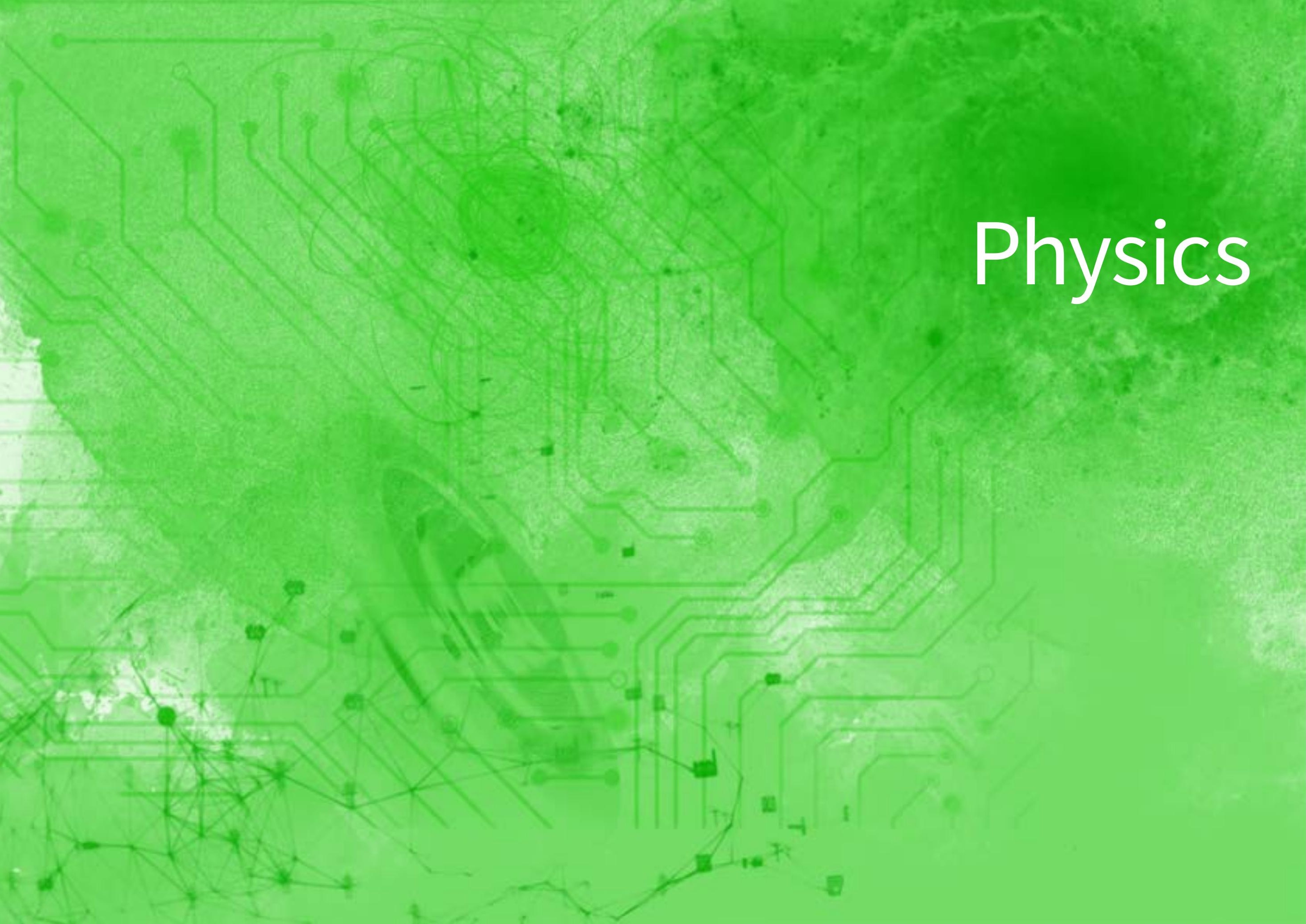


We recognize David Awschalom and Arthur C. Gossard,

This insight into how electrons behave under the influence

of magnetic fields promises application in many areas,

including quantum computing.

\section{David Awschalom Arthur C. Gossard}

Liew Family Professor in Molecular Engineering Institute for Molecular Engineering,

University of Chicago, Chicago, USA
Professor Emeritus and Research Professor,

Materials and Electrical \& Computer

Engineering, University of California

Santa Barbara, Santa Barbara, USA
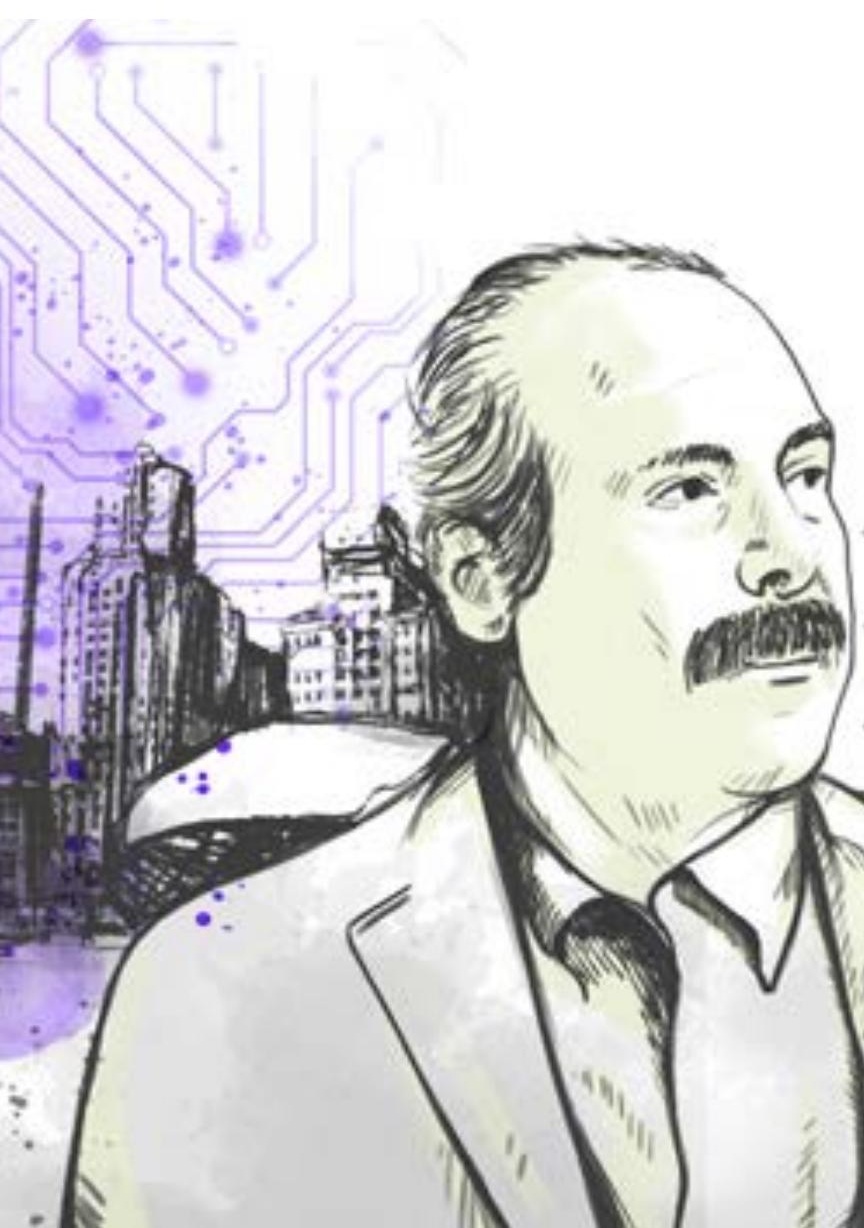

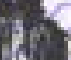

n.

$\because$

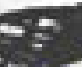
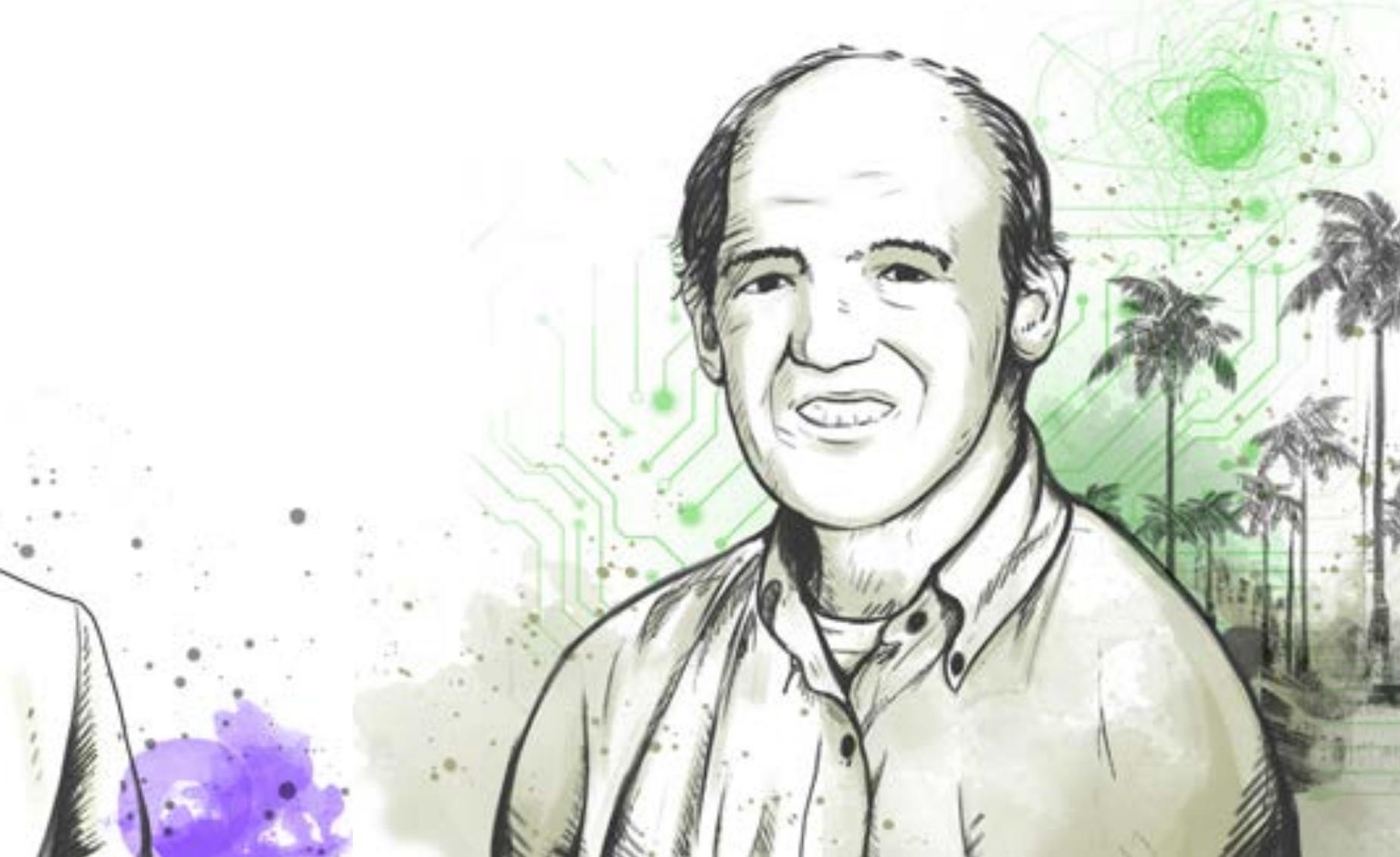
We recognize Sandra M. Faber for pioneering methods to determine the age, size and distance of galaxies and for other contributions to cosmology, including work on

the "cold dark matter" believed to constitute the universe's "missing" matter.

\section{Sandra M. Faber}

Professor Emerita of Astronomy and Astrophysics, University of California Santa Cruz, Santa Cruz, USA
For pioneering methods to determine the age, sizeand distance of galaxies and for other contributions to cosmology

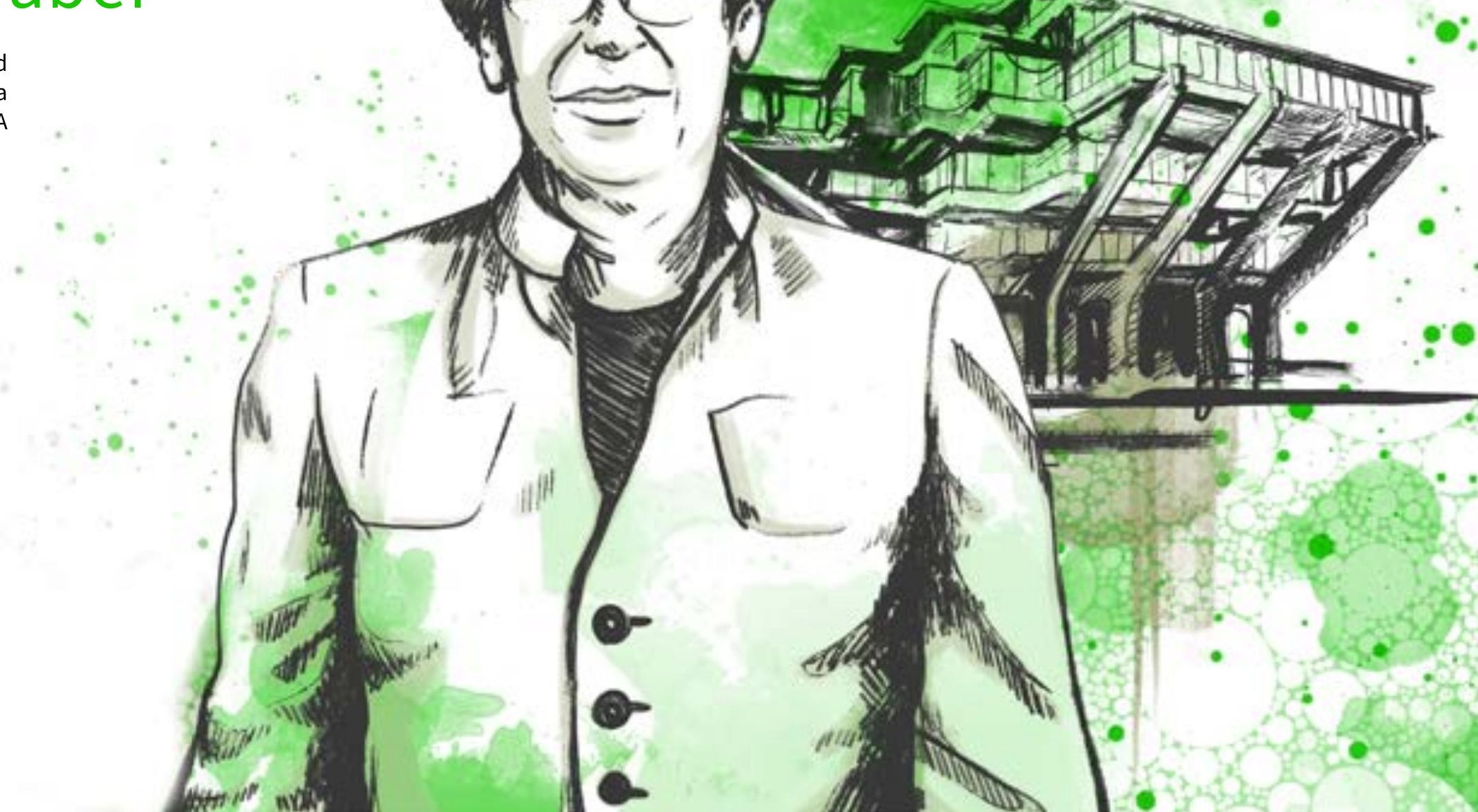


For discoveries advancing the understanding and development of carbonbased materials, including for capacitive energy storage and understanding the mechanisms of operation of supercapacitors
We recognize Yury Gogotsi, Rodney S. Ruoff and Patrice Simon for discoveries advancing the understanding and development of carbon-based materials including for capacitive energy storage and understanding the mechanisms of operation of supercapacitors.

\section{Yury Gogotsi Rodney S. Ruoff}

Distinguished University and Charles T. and Ruth M. Bach Professor, Department

of Materials Science and Engineering,

and A.J. Drexel Nanomaterials Institute, Drexel University, Philadelphia, USA
IBS Director of the Center of Multidimensional Carbon Materials and Distinguished Professor, Ulsan National Institute of Science and Technology, Department of

Chemistry and Schools of Materials Science and Engineering and Energy and Chemical Engineering, Ulsan, South Korea

\section{Patrice Simon}

Professor in Materials Science, Université Paul Sabatier Toulouse III - CNRS, Toulouse, France

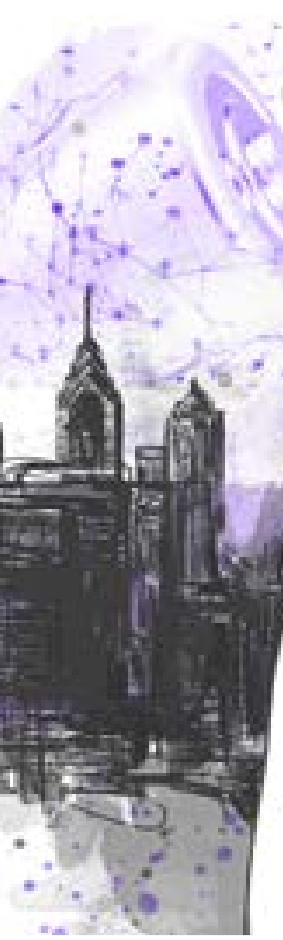

(1)

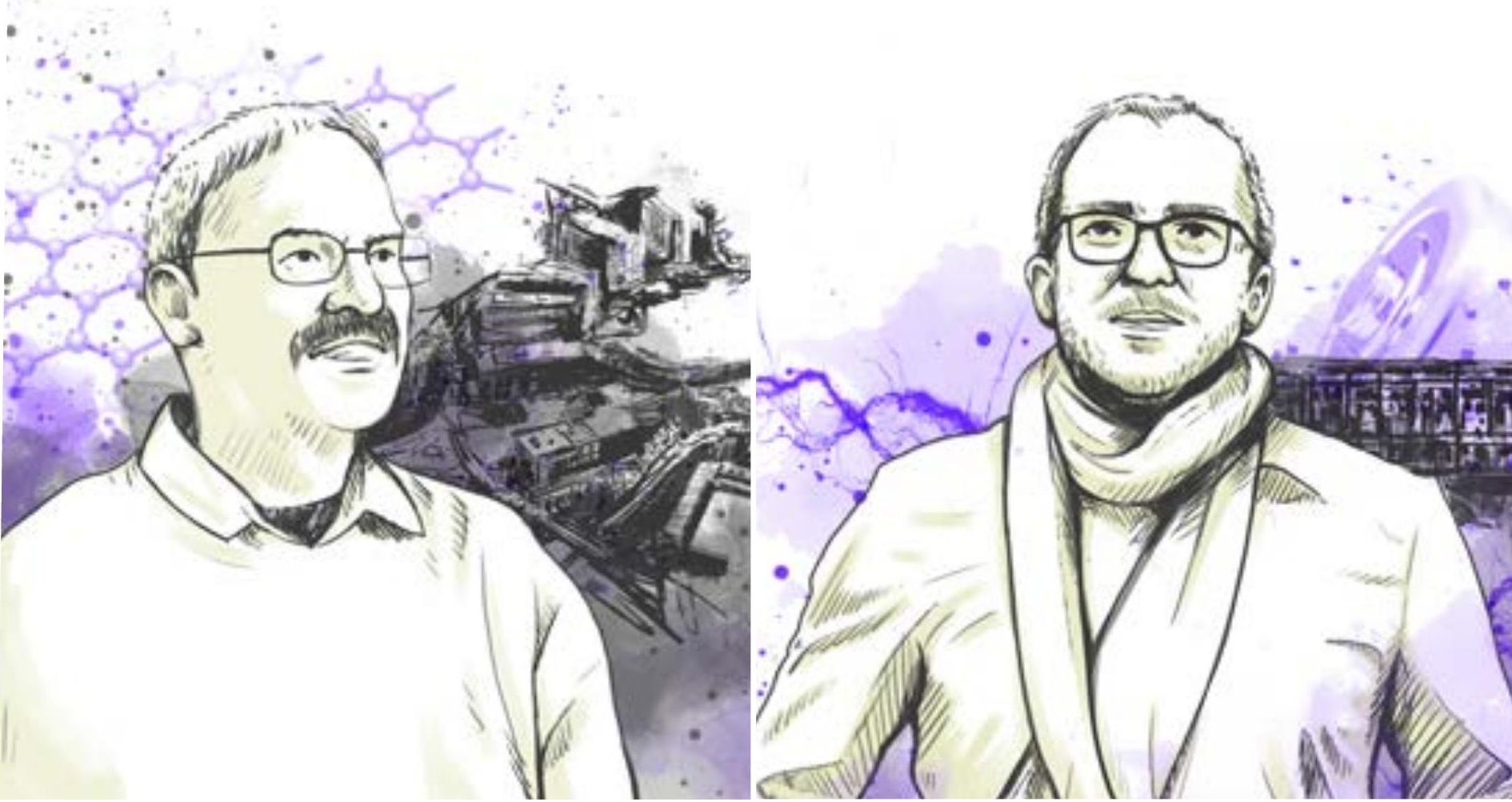




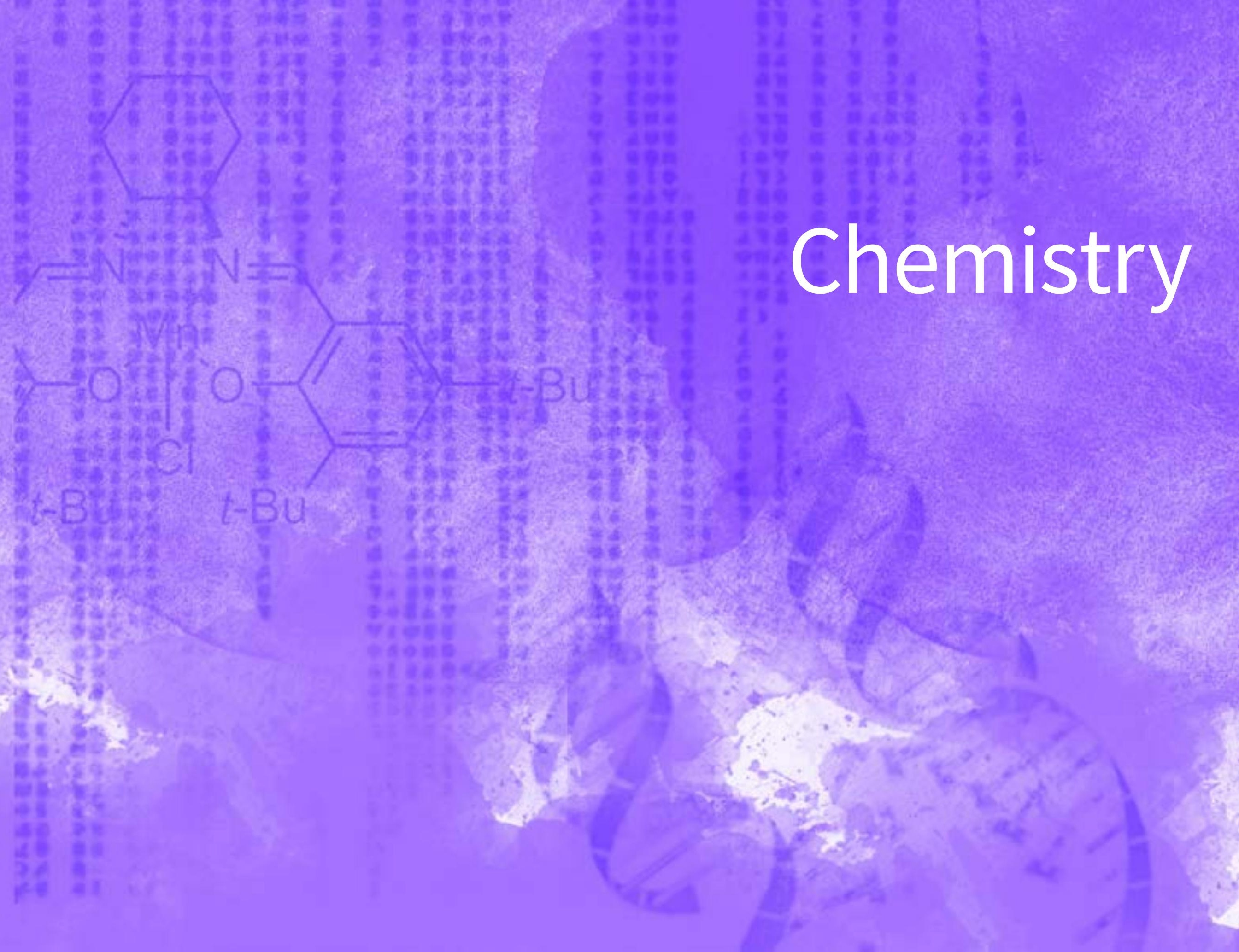


For contributions to catalytic reactions fo organic synthesis
We recognize Eric N Jacobsen for contributions to catalytic reactions

for organic synthesis, especially for the development of Jacobsen epoxidation.

\section{Eric N. Jacobsen}

Sheldon Emery Professor of Chemistry,

Department of Chemistry and Chemical

Biology, Harvard University, Cambridge,

USA 

We recognize JoAnne Stubbe for her discovery that ribonucleotide reductases transform ribonucleotides

into deoxyribonucleotides by a

free-radical mechanism. These

deoxyribonucleotides, in turn, are fundamental to the synthesis and repair of DNA.
For her discovery that

ribonucleotide reductases

transform ribonucleotides

into deoxyribonucleotides

by a free-radical mechanism

\section{JoAnne Stubbe}

Novartis Professor of Chemistry Emerita, Department of Chemistry, MIT, Cambridge, USA 


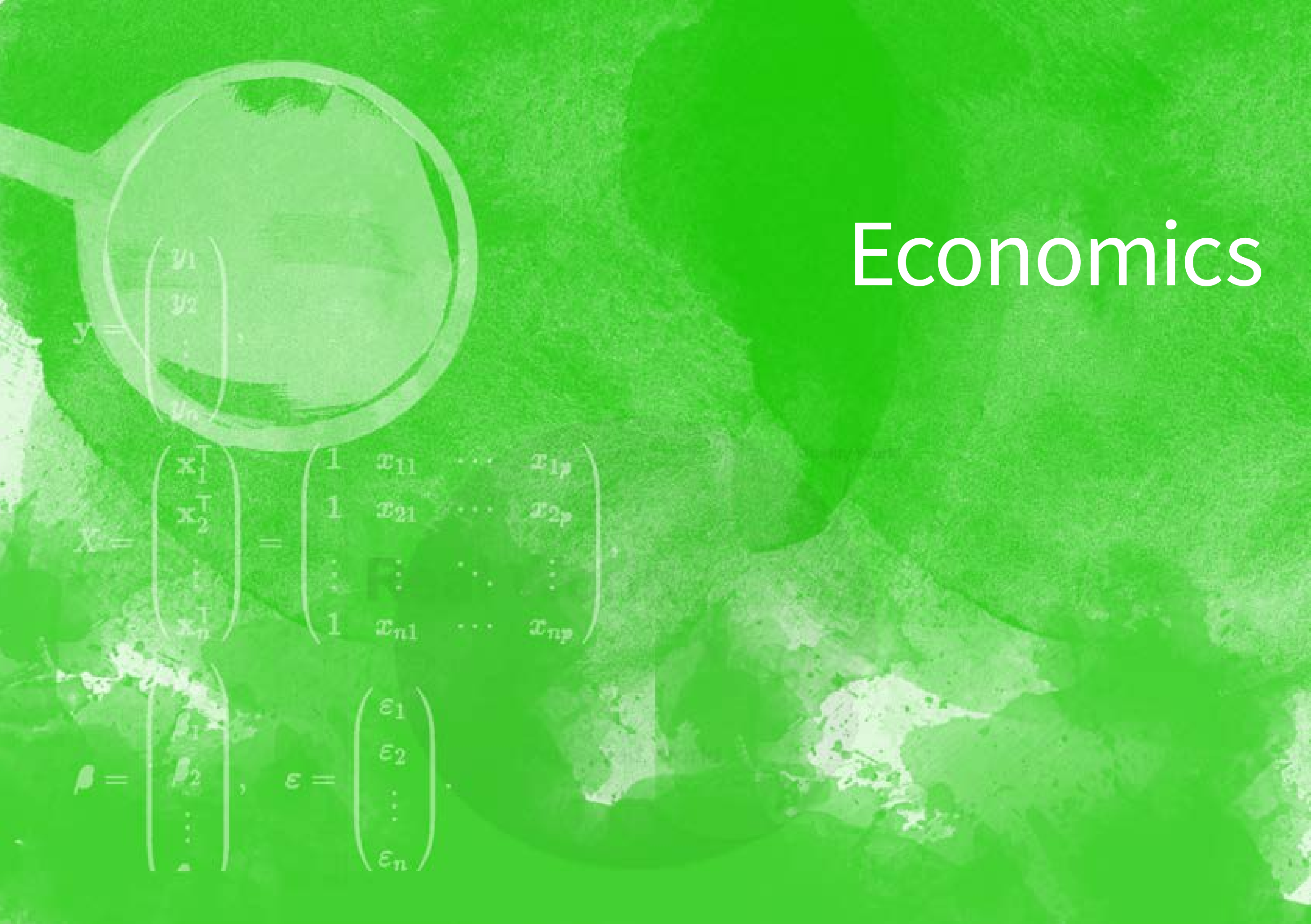


For contributions to panel data analysis, especially the Arellano-Bond estimator
We recognize Manuel Arellano and Stephen R. Bond for contributions to panel data analysis, especially the Arellano-Bond estimator. This method exploits time patterns in panel data to estimate the economic response to a change in a policy or other variable,

while controlling for permanent unobserved confounding variation.

\section{Manuel Arellano Stephen R. Bond}

Professor of Econometrics, CEMFI, Madrid, Spain

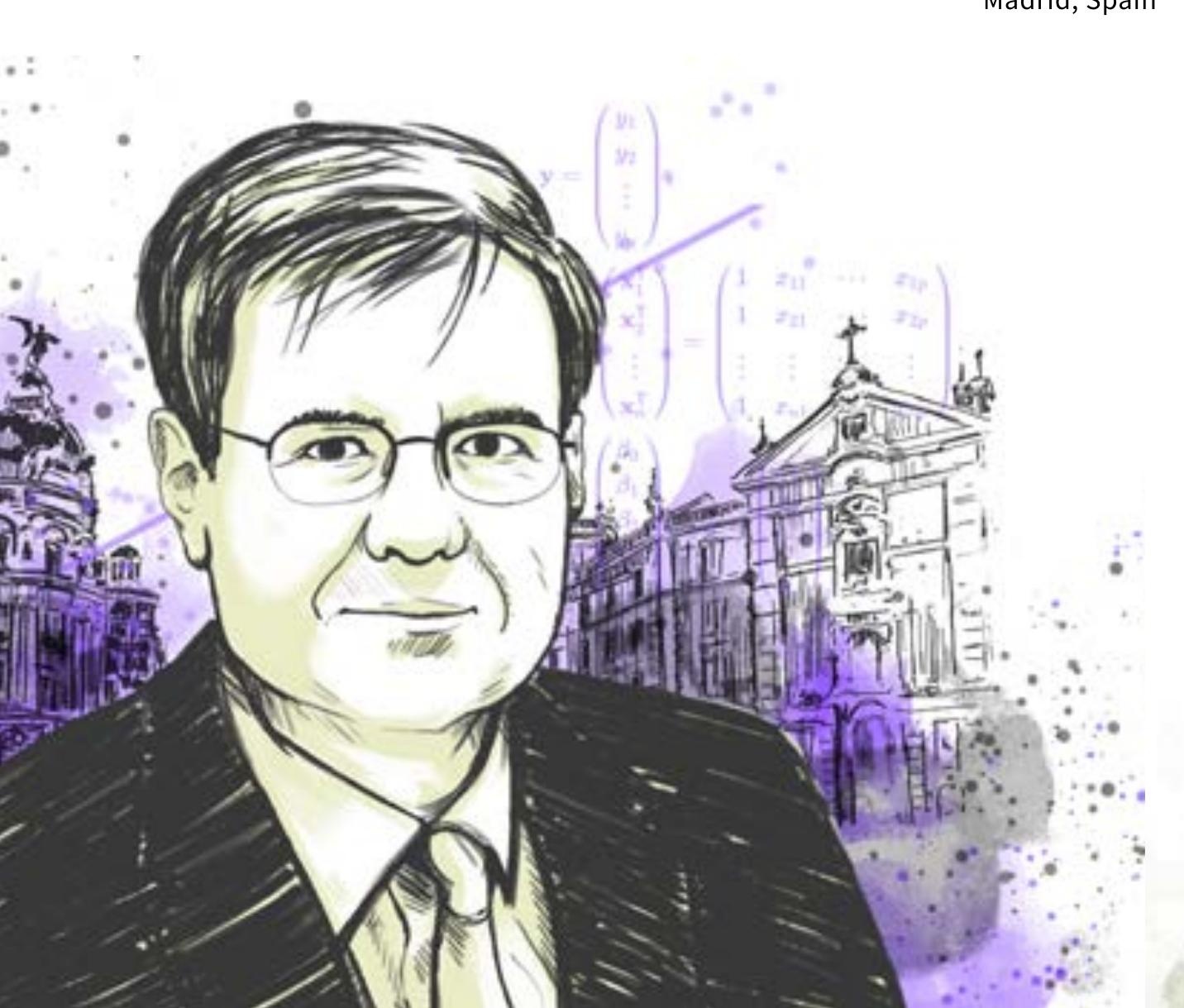

Senior Research Fellow, Department of Economics and Nuffield College, Oxford University, Oxford, United Kingdom

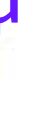

(1)
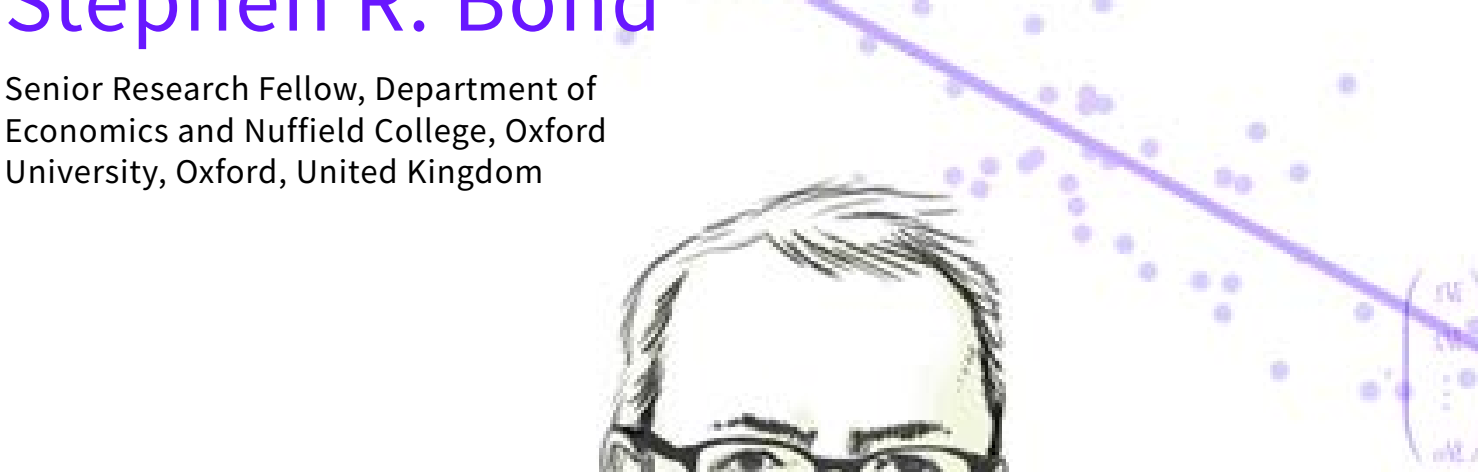
For contributions to

dynamic economic phenomena

We recognize David M. Kreps for contributions to dynamic economic phenomena, in choice theory, finance, game theory, and organization theory.

\section{David M. Kreps}

Adams Distinguished Professor of Management and Professor of Economics, Stanford University Graduate School of Business, Stanford, USA

\section{(1) . 1 igs} talis .

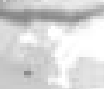
atif

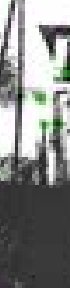

$=1$
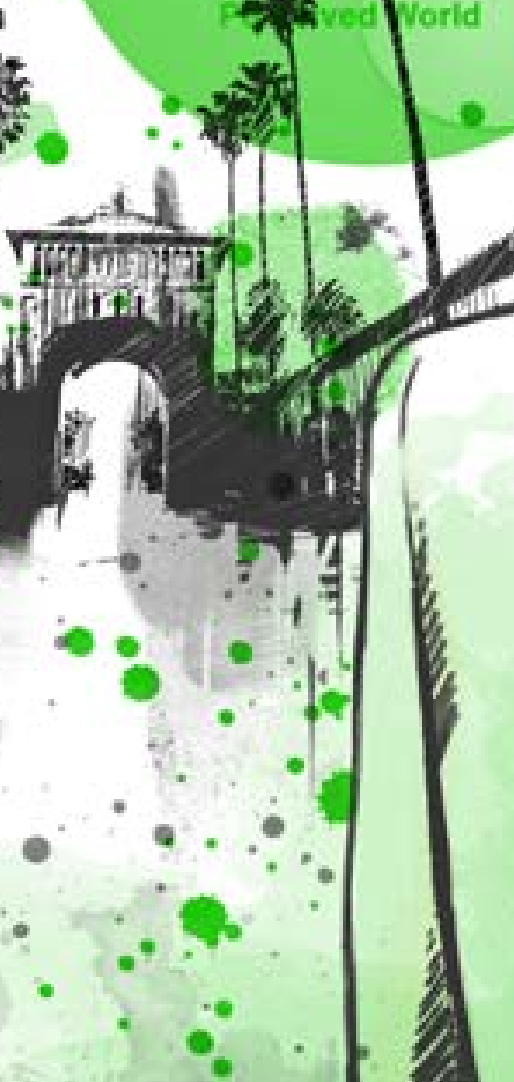

1
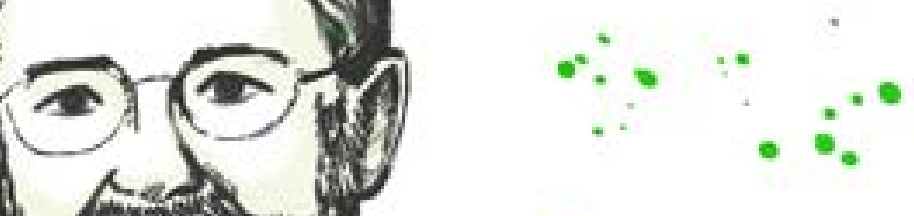

N(s)

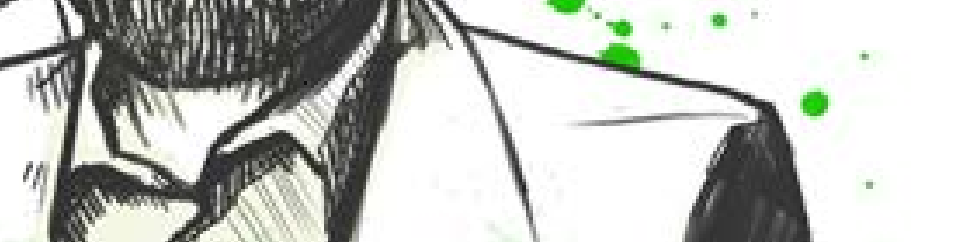

$\because$ 
To find out more about the 2018

Citation Laureates, go to clarivate.com/2018-citation-laureates

\section{About Clarivate Analytics}

Clarivate Analytics is the global leader in providing trusted insights and analytics

to accelerate the pace of innovation. Building on a heritage going back more than acentury and a half, we have built some of the most trusted brands across

the innovation lifecycle, including Web of Science, Cortellis, Derwent,

CompuMark, MarkMonitor and Techstreet. Today, Clarivate Analytics is a new and independent company on a bold entrepreneurial mission to help our clients radically reduce the time from new ideas to life-changing innovations.

For more information, please visit clarivate.com

\section{About Web of Science}

Web of Science is the world's most trusted and largest publisher-neutral citation index, powering global discovery and citation analytics across the sciences, social sciences and art \& humanities. With over 1.4 billion cited references going back to 1900 and millions of users per day - from leading government and academic institutions and researchintensive corporations - Web of Science citation network serves as the foundation for the Journal Impact Factor, InCites and other powerful and trusted citationimpact measures. The Web of Science helps researchers, research institutions, publishers and funders discover and assess the citation impact of over a century of research publications found in the most prestigious journals, books, and conference proceedings.

\section{To learn more about Web of Science, visit: clarivate.com/web-of-science}

\section{About Institute for Scientific Information (ISI)}

ISI is the 'university' of the Web of Science Group at Clarivate Analytics: it maintains the knowledge corpus upon which Web of Science and related information and analytical content, products and services are built; it disseminates that knowledge internally through reports and recommendations and externally through events, conferences and publications; and it carries out research to sustain, extend and improve the knowledge base. 